\title{
Can the dataset of field based recharge estimates in Australia be used to predict recharge in data-poor areas?
}

\author{
R. S. Crosbie ${ }^{1}$, I. D. Jolly ${ }^{1}$, F. W. Leaney ${ }^{1}$, and C. Petheram ${ }^{2}$ \\ ${ }^{1}$ Water for a Healthy Country National Research Flagship, CSIRO Land and Water, Glen Osmond, Australia \\ ${ }^{2}$ Water for a Healthy Country National Research Flagship, CSIRO Land and Water, Canberra, Australia \\ Received: 22 July 2010 - Published in Hydrol. Earth Syst. Sci. Discuss.: 13 August 2010 \\ Revised: 13 October 2010 - Accepted: 16 October 2010 - Published: 25 October 2010
}

\begin{abstract}
Effective management of water resources requires that all elements of the water balance be estimated. Groundwater recharge measurements are difficult, time consuming and expensive. In some cases a field study cannot be justified and simple empirical relationships are used to estimate recharge, and often the value chosen is simply a percentage of rainfall. This paper aims to use a database of 4386 field based estimates of recharge from 172 studies in Australia to produce simple empirical relationships that relate recharge to nationally available datasets and hence can be used to estimate recharge in data-poor areas in a scientifically defensible way.

It was found that the vegetation and soil type were critical determinants in forming relationships between average annual rainfall and average annual recharge. Climate zones and surface geology (lithology) were not found to be significant determinants in the relationship between rainfall and recharge. The method used to estimate recharge had an impact upon the magnitude of the recharge estimates due to the spatial and temporal scales over which the different methods estimate recharge.

Relationships have been developed here between average annual rainfall and average annual recharge for combinations of soil and vegetation type that can be used with only nationally available datasets to provide a recharge estimate. These relationships can explain $60 \%$ of the variance in recharge measurements across Australia. The uncertainty in the recharge estimated using these relationships is generally greater than an order of magnitude. This means that if these relationships are used to help determine water allocations, then the precautionary principle should limit allocations to
\end{abstract}

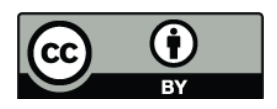

Correspondence to: R. S. Crosbie (russell.crosbie@csiro.au) less than about $5 \%$ of the estimated recharge. If allocations are greater than this, a more detailed site specific study is warranted.

\section{Introduction}

The primary requirement for management of water resources in any region is an accurate knowledge of the water balance. This, in turn, requires estimation of groundwater recharge rates and, where possible, knowledge of their spatial distribution. When formulating a water balance for a region, managers address recharge estimation in many different ways. The amount of time and money expended depends on many factors but is primarily decided by the value of the groundwater resource, the likely scrutiny of the decision and data already available. In many data sparse, less resource intensive areas of Australia, recharge has simply been estimated as a percentage of rainfall, often with no justification. While simple approaches like this can have a large uncertainty, pragmatically they are the only option for estimating recharge in many less resource intense areas and consequently there is a need to develop more scientifically robust and defendable approaches for estimating recharge in these areas. In this paper we aimed to provide a simple, but defensible empirical approach to estimate recharge in data-poor areas based upon existing recharge studies conducted in Australia over the past 65 years. This was done by relating recharge to a number of climatic and landscape attributes.

There have been many previous reviews of groundwater recharge worldwide. Some of these focused upon methods of estimating recharge (Lerner et al., 1990; Scanlon et al., 2002) while others focused on processes (de Vries and Simmers, 2002; Simmers, 1997). The most recent review of field

Published by Copernicus Publications on behalf of the European Geosciences Union. 
studies was conducted by Scanlon et al. (2006) who reviewed 140 recharge studies in (semi-) arid regions from all continents. They produced a single relationship between rainfall and recharge under native vegetation based on studies from different continents.

Most previous reviews of Australian recharge studies have been of limited geographical extent or constrained by a paucity of data. Kennett-Smith et al. (1994) reviewed 18 studies conducted in the south-west Murray Basin and produced a relationship between percentage clay content of the soil and deep drainage. Cook et al. (2001) revisited this work some years later but did not update the relationship. Petheram et al. (2002) undertook the most comprehensive review to that time with a national focus. They used 41 studies to develop relationships between rainfall and recharge for different combinations of land use and soil type but the relationships were based on data of limited geographical extent and were confined to just two land uses types. Tolmie and Silburn (2003) reviewed studies from the Queensland portion of the Murray-Darling Basin but did not attempt to generalise the results. Silberstein (2010) reviewed all the data from the Gnangara groundwater mound in Western Australia with an emphasis on plantation forestry. Interestingly this region was excluded by Petheram et al. (2002) because the recharge measurements were so much greater than those measured elsewhere in the country. The most recent review of Australian recharge field studies, conducted by Crosbie et al. (2010a), collated 4386 recharge estimates from 172 studies nationally and but did not attempt to produce any robust relationships from this data.

The hypothesis that was tested in this paper was that there is enough information contained in the 4386 recharge estimates collated by Crosbie et al. (2010a) to develop generic relationships for estimating recharge in data-poor areas in Australia that rely only upon nationally available datasets. This builds upon the work of Petheram et al. (2002) and Scanlon et al. (2006) to develop relationships for estimating recharge using nationally available datasets such as vegetation type, climate and surface materials.

\section{Methods}

Only those studies that measured dryland diffuse recharge or inferred dryland diffuse recharge through measurements were reviewed. Studies that measured recharge under irrigation were excluded from this analysis because recharge estimates under irrigation are confounded by the numerous land and water management decisions that take place at the paddock scale in these areas (e.g. irrigation technology, irrigation timing, application of soil ameliorants to change infiltration characteristics). We also did not develop generic relationships of recharge from streams due to a lack of field based measurements for this form of recharge. Groundwater modelling and soil moisture modelling studies were also excluded from the analysis due to the wide variability in the robustness of model calibration, which would have necessitated each calibrated model to be individually assessed for inclusion in the study.

Throughout this paper the term "recharge" is used generically. There are many variations of this term that have a specific meaning. For this paper they are:

- Gross recharge - is the water that infiltrates past the root zone, crosses the plane of the water table, and increases the storage of water in the saturated zone.

- Potential recharge - is water that has infiltrated past the root zone of the vegetation (deep drainage). It will become recharge if there are no impeding layers between the root zone and the aquifer. If a land use change has occurred there will be a delay before the rate of potential recharge is equal to the rate of gross recharge, this delay could be decades or longer.

- Net recharge - is the gross recharge minus the amount of water extracted by evapotranspiration from the saturated zone. Net recharge is usually associated with estimates of recharge using the chloride mass balance method in the saturated zone in areas with a shallow water table.

The data analysed in this paper were provided by a review of all field based estimates of recharge in Australia conducted by Crosbie et al. (2010a). This review collated 4386 recharge estimates from 172 studies throughout the country (Fig. 1). These studies used many different techniques for estimating recharge including water table fluctuations, chloride mass balances, and radiogenic isotopes. These techniques estimate recharge at a variety of spatial and temporal scales. The recharge estimates and the attributes collected from the studies are recorded in a database available as an online supplement to this paper along with the full citation of each study. No attempt has been made to evaluate the validity of the recharge estimates; but they were not entered into the database if the author of the study provided a reason why they were unreliable. The better field studies for the purpose of this paper are the ones that provided the most contextual information to help understand the recharge estimates, an example of this is shown in Fig. 1 where only about one quarter of recharge estimates had a vegetation type recorded by the original author.

\subsection{Factors affecting recharge}

Recharge is controlled by many processes that depend upon many factors. At its simplest, the process of recharge is that of rainfall infiltrating into the soil, passing beyond the root zone and reaching the water table. Recharge is the residual after evapotranspiration and runoff have occurred. This section sought to identify the primary factors controlling 


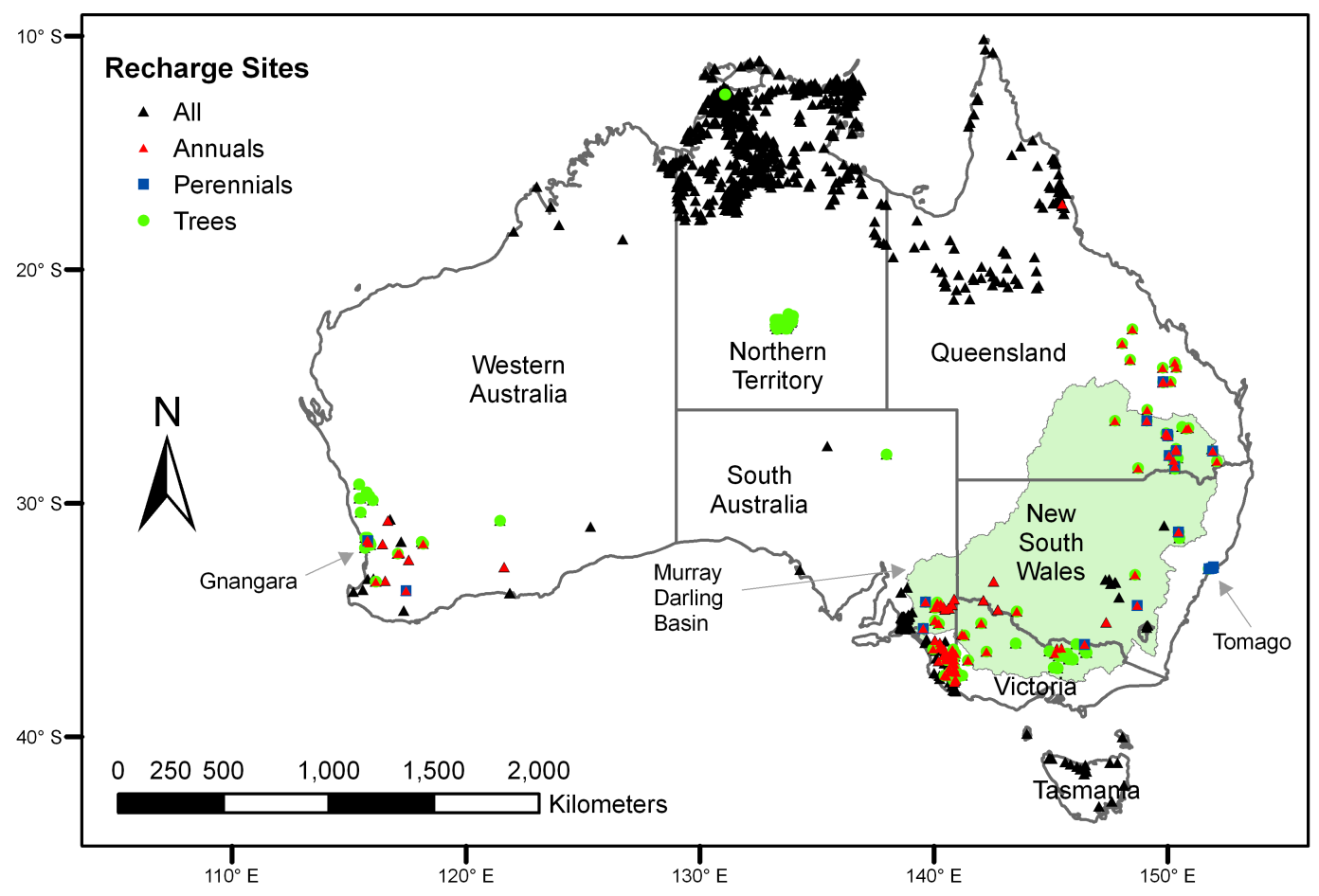

Fig. 1. Location of field sites where recharge has been measured also showing where the different vegetation types were recorded. The class "all" is all the recharge estimates irrespective of vegetation type.

recharge. The factors under consideration were: vegetation; climate; and, surface material. Slope was also considered, but the recharge estimates available were conducted in predominately flat areas; $88 \%$ of recharge estimates were made with less than $2 \%$ slope (data not shown). We also considered the methods used to estimate recharge because this often related to what was actually being measured (deep drainage, recharge, net recharge) and the timeframe over which the measurement applied.

\subsubsection{Methods of recharge estimation}

Different methods estimate recharge over different spatial and temporal scales and at different depths in the soil profile (Petheram et al., 2002). Consequently it is often recommended that more than one method of estimating recharge should be used in a field study (Scanlon et al., 2002; Zhang and Walker, 1998). The database of Crosbie et al. (2010a) categorised the methods used to estimate recharge into 10 groups: steady-state chloride mass balance of groundwater; steady-state chloride mass balance of soil water; transient chloride mass balance of soil water; Water table fluctuation; Water balance (includes lysimetry and soil moisture measurements); Carbon-14 groundwater dating; Chlorofluorocarbon groundwater dating; Tritium groundwater dating; Chlorine-36 groundwater dating; and, Bromide addition and recovery in the unsaturated zone.
Where methods from two different groups were used to estimate recharge at the same site by the same author, the estimated recharge values were compared to evaluate if the method had an influence over the magnitude of the recharge estimate.

\subsubsection{Vegetation}

It is well accepted that vegetation is a primary control on groundwater recharge. Many decades of research into soil, surface water and groundwater salinity has shown that the replacement of deep-rooted native vegetation with shallow rooted annual vegetation results in an increase in recharge (Wood, 1924) by up to two orders of magnitude in semi-arid areas (Allison et al., 1985). Where vegetation type was specified by the authors of the original recharge estimates, they were aggregated into three broad groups as used by Petheram et al. (2002): Annuals; Perennials; and Trees. These three groups were investigated separately due to their known influence upon recharge. A separate analysis was conducted using all available data irrespective of whether the vegetation type was specified or not.

\subsubsection{Climate}

The climate zones of Australia are quite diverse and could be expected to influence recharge. Petheram et al. (2002) cautioned against using generic recharge relationships developed 

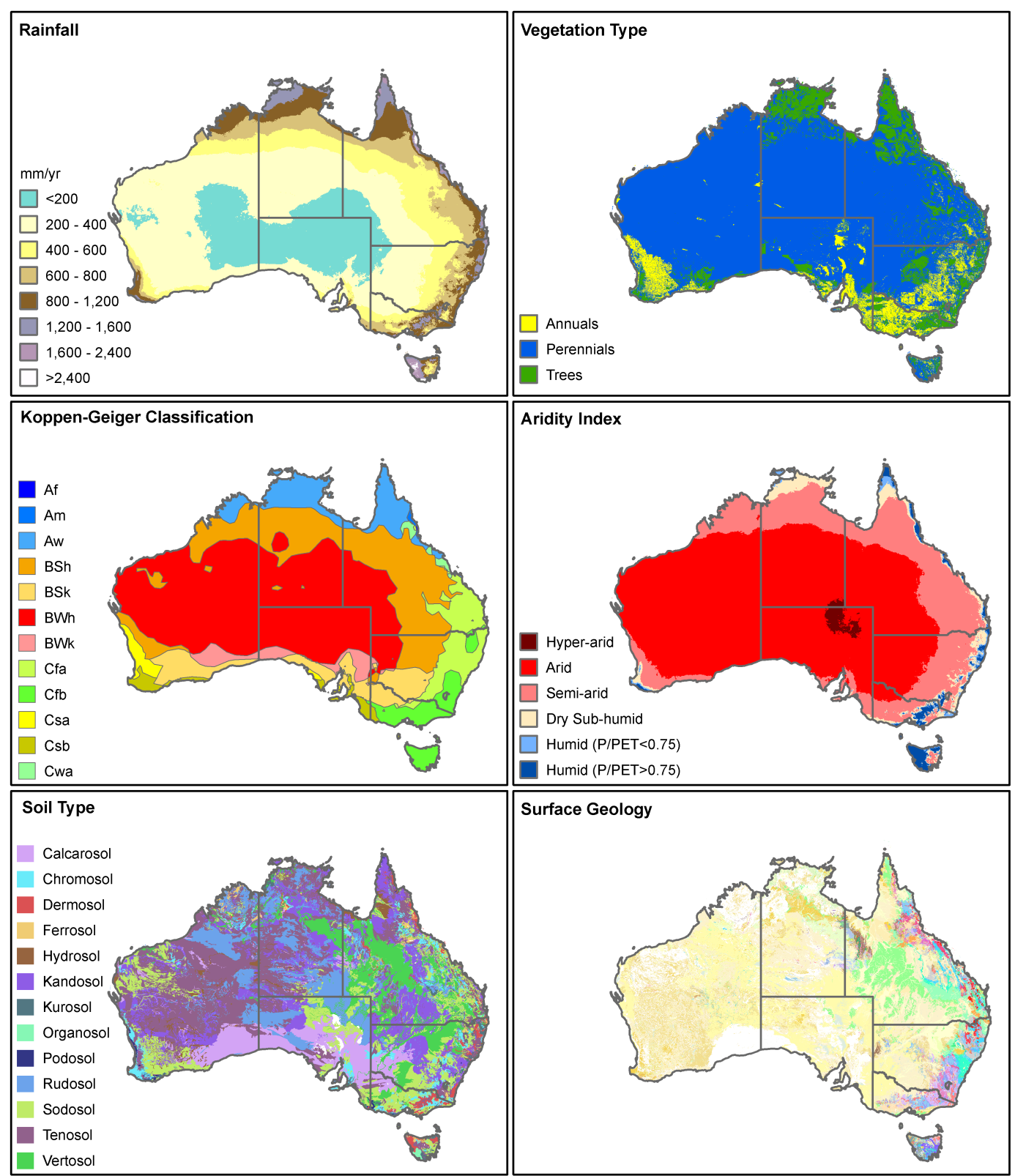

Fig. 2. Factors to be investigated for their influence over recharge. The average annual rainfall is derived from SILO (Jeffrey et al., 2001). The vegetation map is derived from the Integrated Vegetation Coverage 2008 (BRS, 2008). The Köppen-Geiger classification is from Peel et al. (2007). The aridity index map is derived from the rainfall from SILO and the Penman PET of Donohue et al. (2010). The soil type map comes from ASRIS (Johnston et al., 2003). The surface geology map is the 1:1,000,000 map prepared by GA (Liu et al., 2006; Raymond et al., 2007a, 2007b, 2007c; Stewart et al., 2008; Whitaker et al., 2007, 2008), for the legend to the surface geology map see the original source.

in southern Australia to estimate recharge in northern Australia, the inference here was that the summer dominated high intensity rainfall in northern Australia may produce a different relationship between rainfall and recharge than the winter dominated low intensity rainfall of southern Australia. However, Petheram et al. (2002) did not have the data to investigate this difference between climatic zones. In the context of climate change, Cartwright and Simmonds (2008) speculated that an increase in temperature under a future climate could lead to an increase in recharge due to changes in vegetation. Again they did not have any data to support this hypothesis. Using the Köppen-Geiger climate classification (Peel et al., 2007) (Fig. 2) to separate the data into classes will allow these hypotheses to be tested with a substantial amount of data. The classes used by the Köppen-Geiger classification that have recharge estimates are: Tropical, rainforest (Af); 
Tropical, monsoon (Am); Tropical, savannah (Aw); Arid, steppe, hot (Bsh); Arid, steppe, cold (Bsk); Arid, desert, hot (BWh); Arid, desert, cold (BWk); Temperate, without dry season, hot summer (Cfa); Temperate, without dry season, warm summer $(\mathrm{Cfb})$; Temperate, dry summer, hot summer (Csa); Temperate, dry summer, warm summer (Csb); and, Temperate, dry winter, hot summer (Cwa).

Another climate classification that could be relevant to recharge is the aridity index (AI) (UNEP, 1992) (Fig. 2). Scanlon et al. (2006) used the AI to delineate the (semi-) arid regions of the world but did not use it as a basis for assessing recharge. The $\mathrm{AI}$ is the ratio of rainfall $(\mathrm{P})$ to potential evapotranspiration (PET) and classifies a climate into: hyper-arid $(\mathrm{AI}<0.05)$; arid $(0.05<\mathrm{AI}<0.2)$; semi-arid $(0.2<\mathrm{AI}<0.5)$; dry sub-humid $(0.5<\mathrm{AI}<0.65)$ and humid $(\mathrm{AI}>0.65)$. For the purpose of this study the humid class has been further divided into above and below $\mathrm{AI}=0.75$. The relationship between rainfall and recharge for each class was evaluated separately. The AI was determined using the rainfall from SILO (Jeffrey et al., 2001) and the Penman PET from Donohue et al. (2010).

\subsubsection{Surface materials}

The surface material is also well accepted as a control on recharge. Relationships have been developed between the percentage clay content of surface soils and recharge (Kennett-Smith et al., 1994; Wohling, 2010) and the plant available water capacity of surface soils and recharge (Radford et al., 2009). These parameters are rarely measured as part of recharge investigations and their mapping at the national scale is difficult. For these reasons other properties of the surface materials were investigated that are mapped at the national scale.

The surface geology has been mapped seamlessly across Australia at 1:1,000,000 scale (Fig. 2) (Liu et al., 2006; Raymond et al., 2007a, 2007b, 2007c; Stewart et al., 2008; Whitaker et al., 2007, 2008). When the lithologies in the attribute table were compared with our database, it was clear that there were too many lithologies to enable a comparison between them. To overcome this problem the lithologies were simplified into classes: Volcanic; Plutonic; Metamorphic; Weathered; Carbonates; Unconsolidated - course; Unconsolidated - fine; Consolidated - course; Consolidated fine. Unfortunately the mapping does not record karst features or fracturing of the rock that would be expected to be important in estimating recharge. The relationship between rainfall and recharge was analysed separately for each of the classes to determine their significance upon recharge.

As a separate investigation to the surface geology, the dominant soil type was also evaluated for its impact upon recharge. There are national scale soil maps (Johnston et al., 2003) that classify the soils according to the Australian Soils Classification (Isbell, 2002) (Fig. 2). The top level of this classification (Soil Order) was used for grouping recharge estimates and evaluating the relationship between average annual rainfall and average annual recharge as the dominant soil order is the best available national scale mapping.

\subsection{An empirical method for estimating recharge in data-poor areas}

This section sought to use the factors identified in Sect. 2.1 as affecting recharge to produce a method for estimating recharge in data-poor areas across Australia. The intention was that a recharge estimate can be made using national scale datasets as a minimum, but could also be used with more detailed information if available. The authors stress that if the value of the resource is high or the consequences of exploiting the resource are detrimental to sensitive areas, then a detailed investigation is warranted and the results of this method should not be relied upon.

\subsection{Development of relationships between average annual rainfall and average annual recharge}

A relationship between average annual rainfall and average annual recharge for each class from each factor under investigation was developed using a simple one parameter model:

$R=10^{a P}$

where $a$ is a fitting parameter, $R$ is annual average recharge and $P$ is annual average rainfall. The fitting parameter (slope) was determined by least squares regression between annual average rainfall and the logarithm of annual average recharge. The statistical significance of this relationship between rainfall and recharge was determined on the basis of an F-test.

If a relationship exists between rainfall and recharge for two classes (e.g. annual and perennial vegetation), then the 95\% confidence interval about the fitting parameter of each class can be compared to determine if the two classes are significantly different. If the classes are significantly different then that classification is potentially useful as a predictor of recharge.

\section{Results and discussion}

\subsection{Effect of recharge estimation technique on recharge}

The steady state chloride mass balance in the saturated zone (Cl SS GW) (Anderson, 1945) was by far the most frequently used method for estimating recharge in Australia (Fig. 3). It was used in $46 \%$ of studies to produce $77 \%$ of the recharge estimates.

The second most commonly used method for estimating recharge in Australia was the transient chloride mass balance in the unsaturated zone ( $\mathrm{Cl}$ Transient Soil) and accounted for over $9 \%$ of all recharge estimates made. There are several variations on this method with the method developed by 


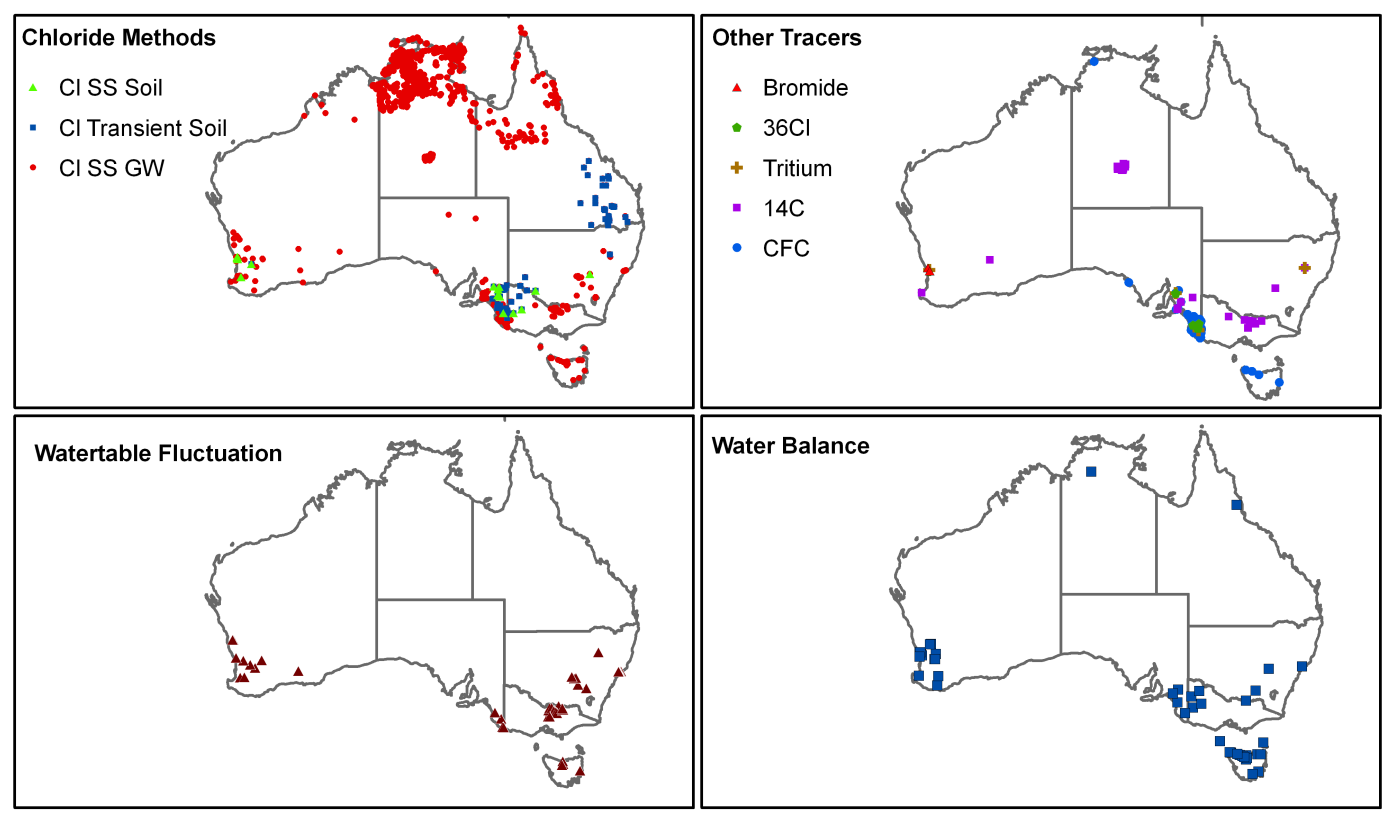

Fig. 3. Locations of studies where the different methods have been used to estimate recharge.

Walker et al. (1991) used predominantly in South Australia and the method of Thorburn et al. (1987) predominantly used in Queensland (Fig. 3).

The water table fluctuation (WTF) method (Meinzer and Stearns, 1929) and the water balance (WB) techniques accounted for over $3 \%$ of recharge estimates each, and the steady state chloride mass balance in the unsaturated zone (Allison and Hughes, 1978) accounted for over 2\% of recharge estimates. The other tracers $\left({ }^{14} \mathrm{C}, \mathrm{CFC},{ }^{3} \mathrm{H},{ }^{36} \mathrm{CL}\right.$ and $\mathrm{Br}^{-}$) only accounted for $4 \%$ of recharge estimates combined.

The diverse range of methods used to estimate recharge allowed comparisons between methods to be made where the same author had made measurements at the same site with multiple techniques (Fig. 4).

Recharge estimates made using the WTF method appear to be much higher than those made using $\mathrm{Cl} \mathrm{SS} \mathrm{GW} \mathrm{or}{ }^{14} \mathrm{C}$ (Fig. $4 a$ and $4 b$ ). The main reason for this is the different timeframes over which these methods operate. The Cl SS $\mathrm{GW}$ and ${ }^{14} \mathrm{C}$ methods are providing an estimate of recharge over the residence time of the water in the aquifer; this can be many thousands of years. The WTF method was providing an estimate of recharge over the length of time that measurements of water levels were recorded; this can be up to decades. In many cases the WTF method was estimating recharge under the current land use and the $\mathrm{Cl} \mathrm{SS}$ $\mathrm{GW}$ and ${ }^{14} \mathrm{C}$ methods were estimating recharge under preclearing conditions, the discrepancy in the recharge estimates was due to a change in land use (Cartwright et al., 2007). Climate change has also been shown to impact recharge estimates over time scales of thousands of years (Leaney et al.,
2003), while climate variability could also impact recharge estimates made over shorter time scales (e.g. droughts). Another reason why the Cl SS GW and WTF methods can produce different estimates of recharge is due to evapotranspiration from the saturated zone. The WTF method is an estimate of gross recharge whereas the $\mathrm{Cl} \mathrm{SS} \mathrm{GW} \mathrm{method} \mathrm{is} \mathrm{an} \mathrm{esti-}$ mate of net recharge, in areas with shallow water tables $\mathrm{Cl}^{-}$ can continue to be concentrated in the saturated zone due to phreatophytic vegetation (Crosbie et al., 2002).

The comparison between the Cl Transient Soil and Cl SS GW shows that at low recharge rates they were quite different but as recharge increased they became more consistent (Fig. 4c). The reason for this is the type of recharge being estimated; the $\mathrm{Cl}$ Transient Soil was an estimate of potential recharge whereas the $\mathrm{Cl} \mathrm{SS} \mathrm{GW}$ was an estimate of actual recharge. After land clearing there is a delay between an increase in potential recharge and an increase in actual recharge, this delay is shorter for higher recharge areas indicating that where the results of the two methods were similar the system had come to a new equilibrium (Jolly et al., 1989).

Where recharge estimation methods are consistent in the type of recharge estimated and the timeframe over which the estimate is made then the estimates can be similar to each other. When the ${ }^{14} \mathrm{C}$ and $\mathrm{Cl} \mathrm{SS} \mathrm{GW}$ methods were compared, the recharge estimates are similar because both methods were estimates of recharge over very long periods of time (Fig. 4d). The WB and Cl Transient Soil were both estimates of potential recharge and the magnitudes of the recharge estimates were also similar with each other even though they may operate at different spatial and temporal scales (Fig. 4e). The WTF and CFC methods were both estimates of gross 

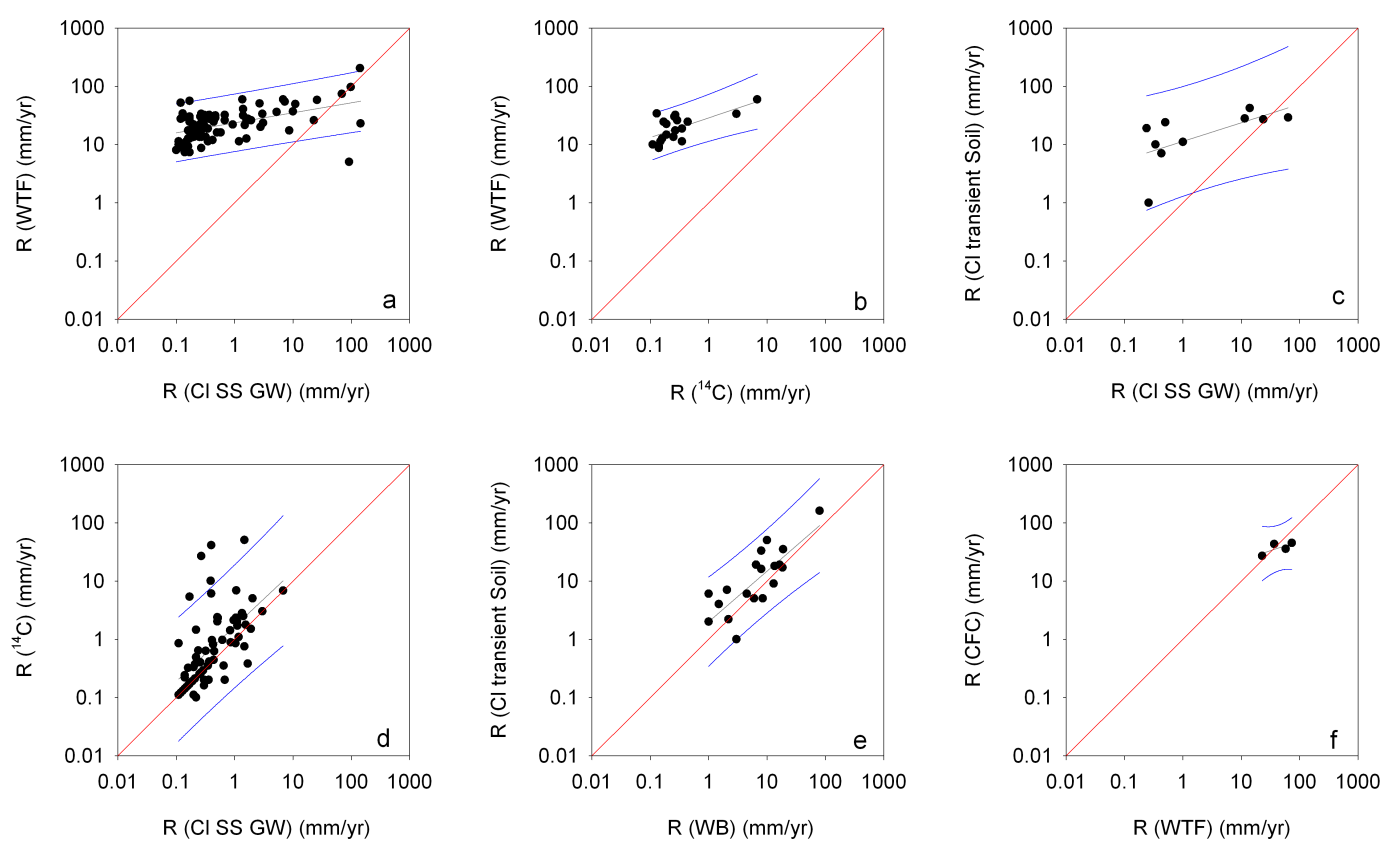

Fig. 4. Comparison of the different methods where two methods have been used at the same site by the same author.

recharge over recent decades and were shown to produce consistent results (Fig. 4f).

This comparison of methods has shown that different methods can give recharge estimates that appear to be very different, but with an understanding of what was actually being measured they can provide complimentary information. This again highlights the need for using multiple methods of estimating recharge as not all methods are suitable for all purposes.

\subsection{Effect of vegetation type on recharge}

When the recharge estimates were averaged for each vegetation type, it was found that the geometric mean was 8.5, 13 and $0.8 \mathrm{~mm} \mathrm{yr}^{-1}$ for the annuals, perennials and trees respectively. A boxplot of the same data (Fig. 5) showed that the median of the annuals was greater than the perennials $\left(13 \mathrm{~mm} \mathrm{yr}^{-1} \mathrm{cf} 7.8 \mathrm{~mm} \mathrm{yr}^{-1}\right)$. This analysis is deceptive because the recharge estimates were spread throughout the country but not evenly, and there were about 10 times more recharge estimates under annuals and trees than there were under perennials.

Where there were paired studies investigating recharge under different land uses at the same site using the same recharge estimation method, recharge under annuals was greater than recharge under perennials or trees, and recharge under perennials was greater than recharge under trees (Fig. 5).

A relationship between rainfall and recharge was established for each of these vegetation groups (Fig. 6). The slopes of these regression lines were all statistically
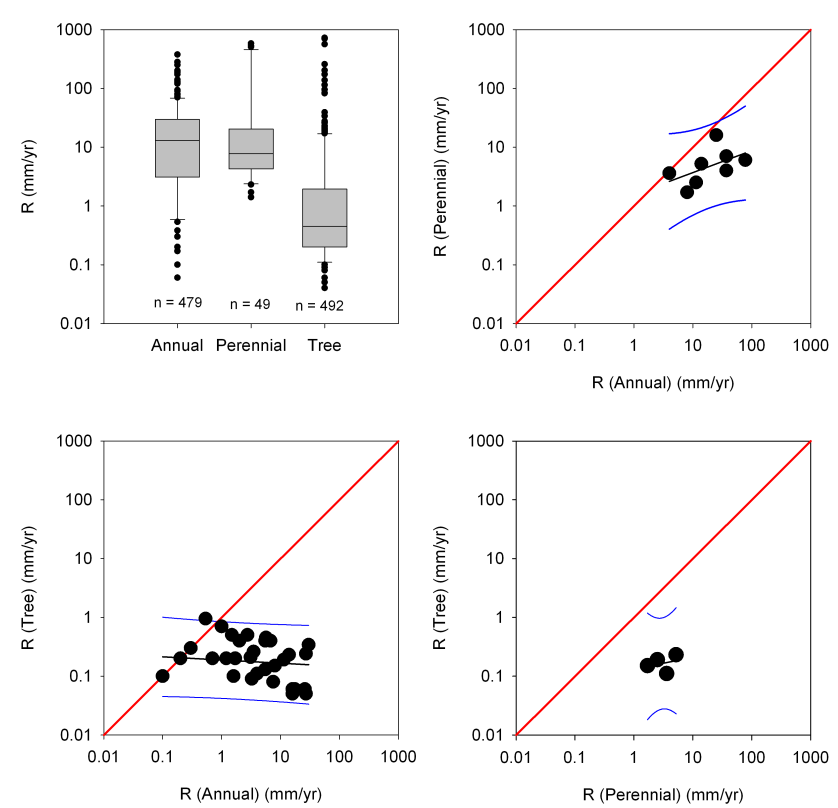

Fig. 5. The influence of vegetation on recharge. The boxplots compare all recharge estimates under the three groups of vegetation types. The scatterplots show where estimates of recharge have been made under two vegetation types at the same site by the same author using the same method.

significantly different $(p<0.05)$ demonstrating that vegetation type is a key parameter in estimating recharge. The trees had the worst fit to the model, which was not unexpected. The tree vegetation class was the closest to the natural state. 


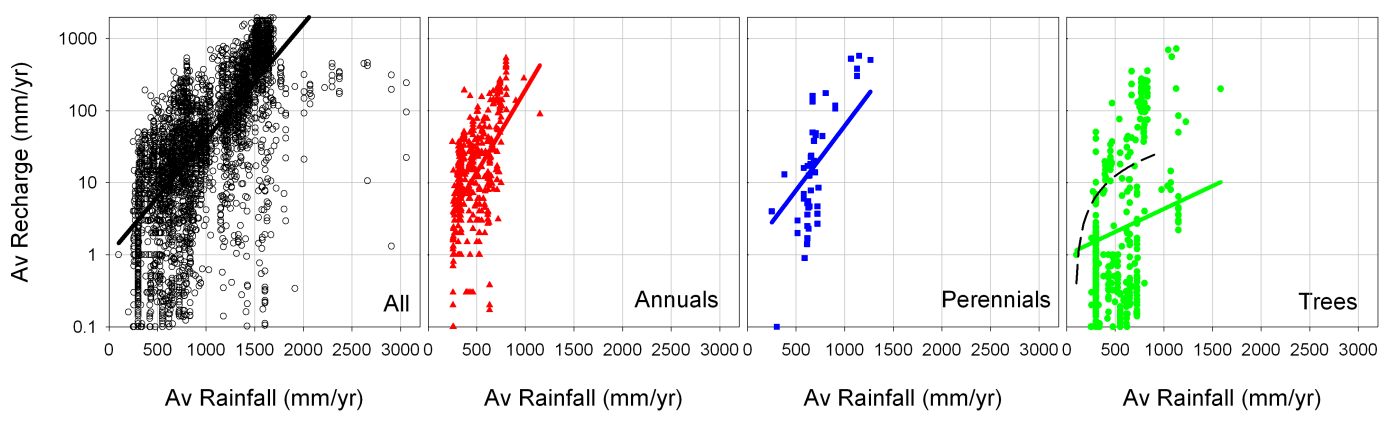

Fig. 6. The relationship between rainfall and recharge for each vegetation type. The black dashed line on the trees plot is the relationship between rainfall and recharge for natural areas developed by Scanlon et al. (2006). The class "all" is all the recharge estimates irrespective of vegetation type.

Ecological optimality theory (Eagleson, 1982) suggests that the vegetation will expand to use as much of the available resources as possible, in a water limited environment rainfall is likely to be the key constraint on growth. Between a rainfall of $300 \mathrm{~mm} \mathrm{yr}^{-1}$ and $800 \mathrm{~mm} \mathrm{yr}^{-1}$ the spread of recharge estimates did not change, above $800 \mathrm{~mm} \mathrm{yr}^{-1}$ the recharge estimates became greater (Fig. 6).

Scanlon et al. (2006) developed a relationship between rainfall and recharge for semi-arid areas under natural vegetation from a global synthesis of recharge studies (including both modelling and field studies). The relationship developed here for recharge under trees predicts substantially less recharge than the relationship developed by Scanlon et al. (2006) (Fig. 6), suggesting that recharge in Australia might be different to the rest of the world. It has been hypothesised that Australian native vegetation may be a key factor contributing to flow characteristics of Australian rivers being different to those in the rest of the world (Peel et al., 2001); the same could be true for recharge. Australia's native vegetation is highly endemic and has evolved deep rooted systems (Canadell et al., 1996) that are able to extract soil water at very low suctions (O'Grady et al., 2008). Unlike other parts of the world of the same Köppen-Geiger types, Australia's native vegetation is predominantly evergreen (Bowman and Prior, 2005; Peel et al., 2001). The significance of this is that lysimetery (Penman, 1967), catchment water balance (Bosch and Hewlet, 1982) and catchment modelling studies (Peel et al., 2001) suggest that actual evapotranspiration is greater from evergreen vegetation than deciduous vegetation. This has also resulted in very saline groundwater in many areas of Australia due to concentration of salt by transpiration (Herczeg et al., 2001).

\subsection{Effect of climate on recharge}

The analysis of the relationship between rainfall and recharge when separated by Köppen-Geiger classes was hampered by a lack of data (Fig. 7). It was not possible to generate meaningful relationships for the tropical classes (Am and
Aw) because they did not have sufficient data where the recharge estimate had an associated vegetation class. Analysis of recharge estimates made in the desert classes (BWh and BWk) was also limited due to a lack of data. The relationship when all data were used is of limited value because of the dependence of recharge upon vegetation.

In the temperate classes, the dry and hot summer class (Csa) had significantly more recharge $(p<0.05)$ than the temperate class without dry season hot summer (Cfa) for a given average annual rainfall for both annual and perennial vegetation. There was insufficient data to create a relationship between rainfall and recharge for the dry winter hot summer class (Cwa). For annual vegetation, the dry and warm summer class (Csb) had significantly more recharge $(p<0.05)$ for a given average annual rainfall than the without dry season warm summer class (Cfb).

This very limited comparison suggests that recharge under a winter dominated rainfall climate is higher than under an equi-seasonal rainfall climate. However, this result was confounded by multiple factors. The recharge estimates in the Csa class were from the Swan Coastal Plain and wheatbelt in Western Australia, which have predominantly sandy soils whereas the Cfa class includes many recharge estimates from heavy textured soils in New South Wales and Queensland. The same problems exist with the warm summer classes Csb and $\mathrm{Cfb}$. Recharge estimates made under Csb were mainly on sand in the south-east of South Australia and recharge estimates made under $\mathrm{Cfb}$ were mainly from Victoria on heavier textured soils. We do not have enough information to conclusively say that winter dominated rainfall produces more recharge than equi-seasonal rainfall for a given mean annual rainfall.

The temperature classes can also be used to investigate whether recharge was greater under a hot climate. The Arid Steppe Hot (BSh) and Cold (Bsk) both have a relationship developed between rainfall and recharge for the annual vegetation class but they are not significantly different from each other. The Dry Summer Hot (Cfa) and Cfb both have a relationship developed between rainfall and recharge for the 


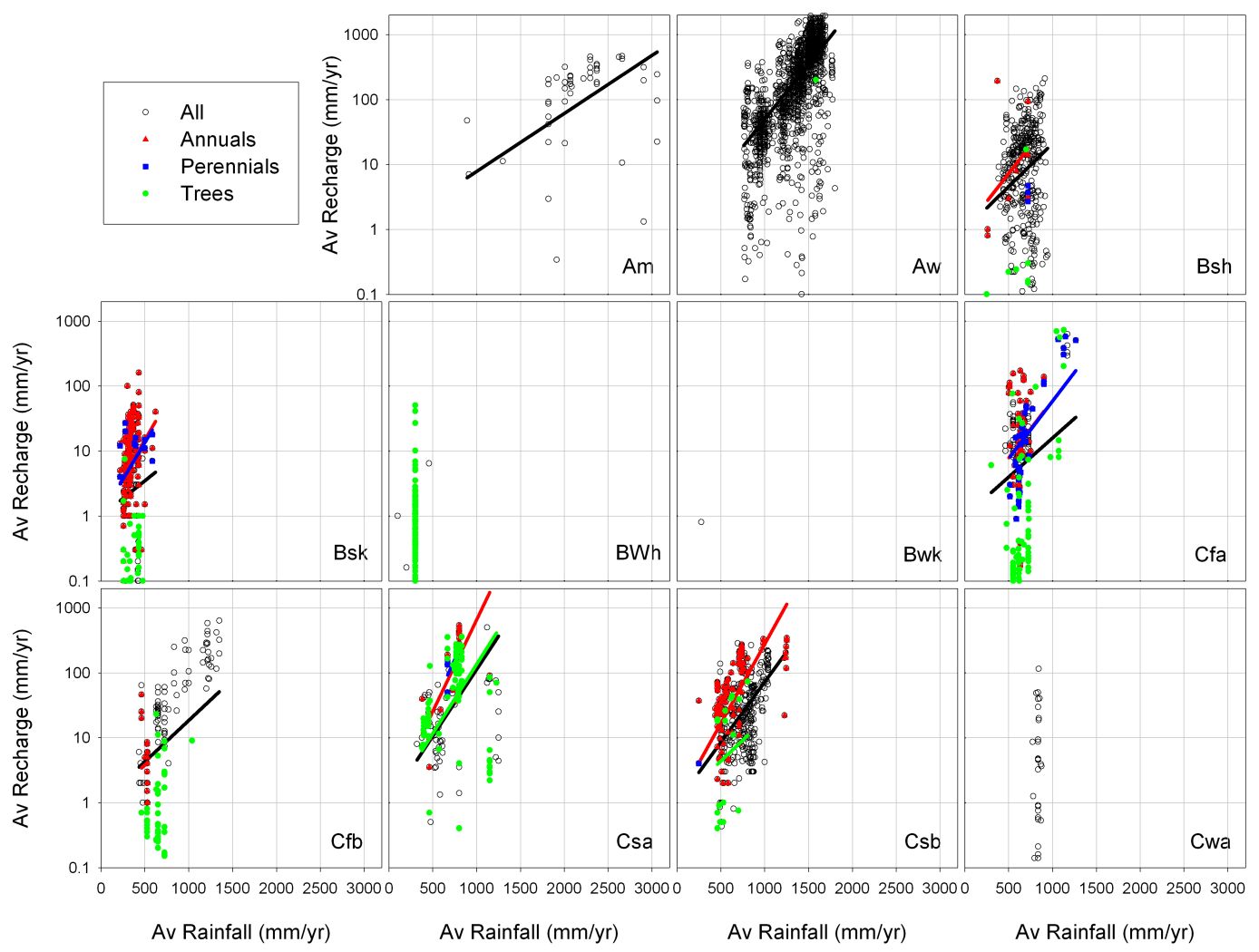

Fig. 7. The relationship between rainfall and recharge for each class from the Köppen-Geiger climate classification scheme. The class "all" is all the recharge estimates irrespective of vegetation type.

annual vegetation class but they are not significantly different from each other. The Csa and Csb classes both have a relationship developed between rainfall and recharge for the annual vegetation class but they are not significantly different from each other. From the information we have available there does not appear to be a difference in recharge with temperature.

The other climate classification investigated was the aridity index (UNEP, 1992) (Fig. 8). Relationships were developed between rainfall and recharge for annual vegetation for the arid, semi-arid and dry sub-humid classes, but these relationships were not significantly different from each other. Relationships were developed between rainfall and recharge for perennial vegetation for the semi-arid, dry sub-humid and humid $(P / \mathrm{PET}<0.75)$ classes. Recharge under the dry sub-humid class was not significantly different from recharge under either the semi-arid or humid $(P / \mathrm{PET}<0.75)$ classes but recharge under the semi-arid class was significantly $(p<0.05)$ different from the humid class $(\mathrm{P} / \mathrm{PET}<0.75)$. The most striking result from the investigation into rainfall-recharge relationships under the different aridity index classes was that there was no relationship between rainfall and recharge for the humid class with P/PET greater than 0.75 .

\subsection{Effect of surface material on recharge}

The relationship between mean annual rainfall and recharge under different classes of surface geology was investigated (Fig. 9). The relationship developed between mean annual rainfall and recharge for annual vegetation for the volcanic, plutonic, weathered and carbonates classes were not significantly different from each other or from the unconsolidated or consolidated classes suggesting that surface geology has little explanatory power for the rainfall - recharge relationship. The relationships developed for annual and perennial vegetation on the unconsolidated - coarse and unconsolidated - fine classes were not significantly different from each other. This result would suggest that the surface geology mapping is not an adequate predictor of recharge.

The majority of the recharge estimates were in the unconsolidated - coarse and unconsolidated - fine classes, suggesting that a soils classification might be more appropriate.

The relationship between rainfall and recharge in classes according to soil order is presented in Fig. 10. Some soil orders did not have sufficient data to develop a relationship between rainfall and recharge for any of the three vegetation classes (CH, DE, FE, HY, KA, OR, RU). The Podosols (PO) had the highest recharge for a given rainfall for all vegetation types, this was not surprising because Podosols are deep 


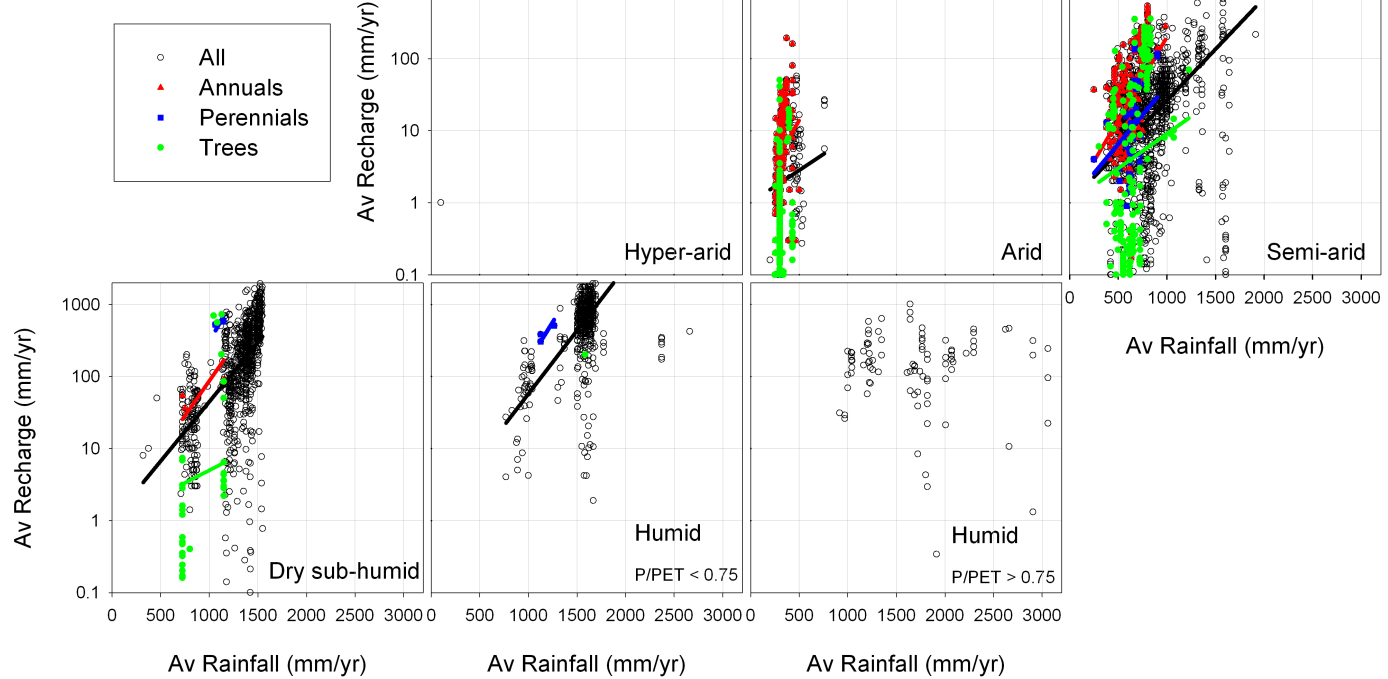

Fig. 8. The relationship between rainfall and recharge when the data is categorised based upon the aridity index. The class "all" is all the recharge estimates irrespective of vegetation type.

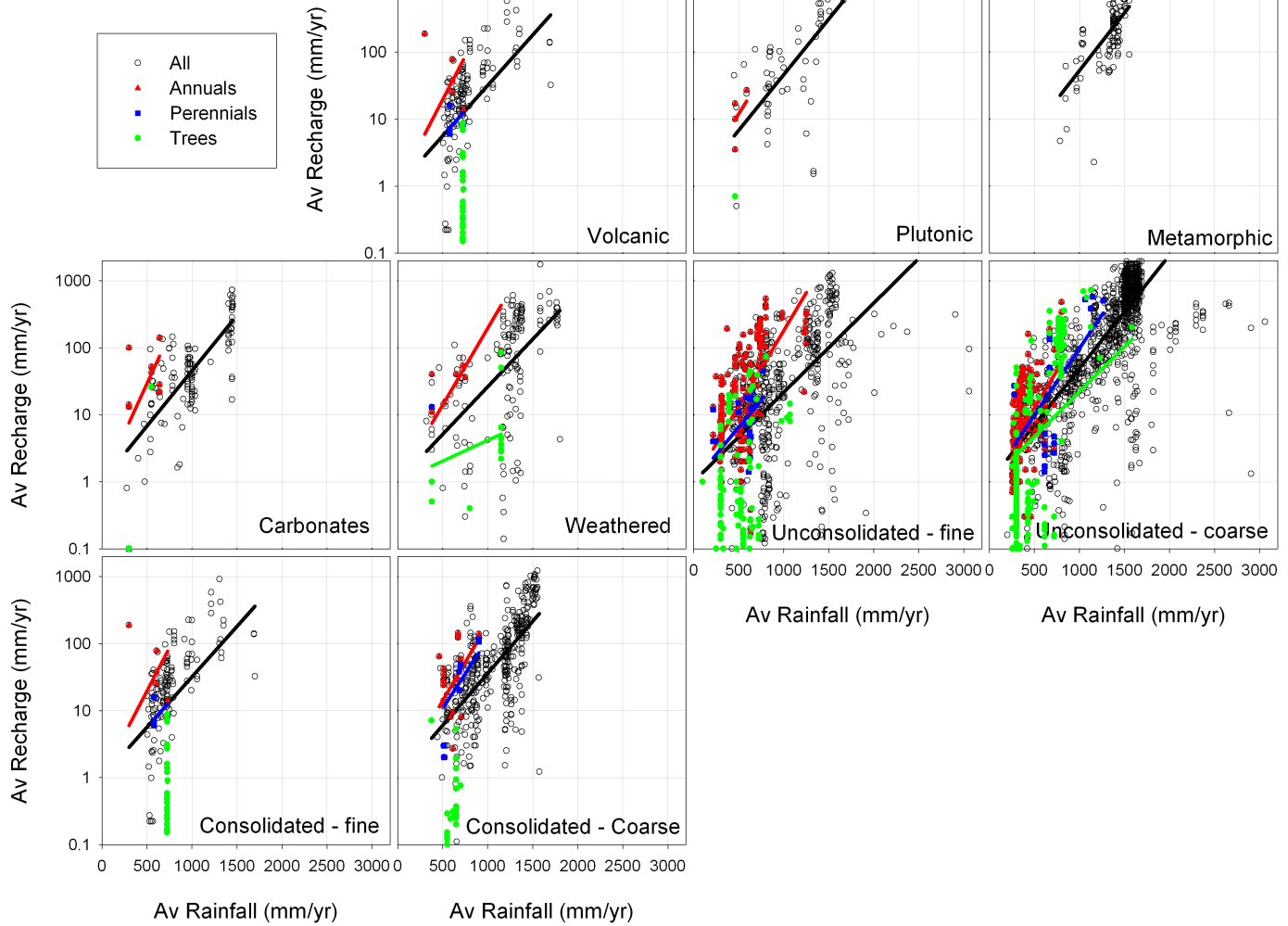

Fig. 9. The relationship between rainfall and recharge when categorised by surface geology groups. The class "all" is all the recharge estimates irrespective of vegetation type. 


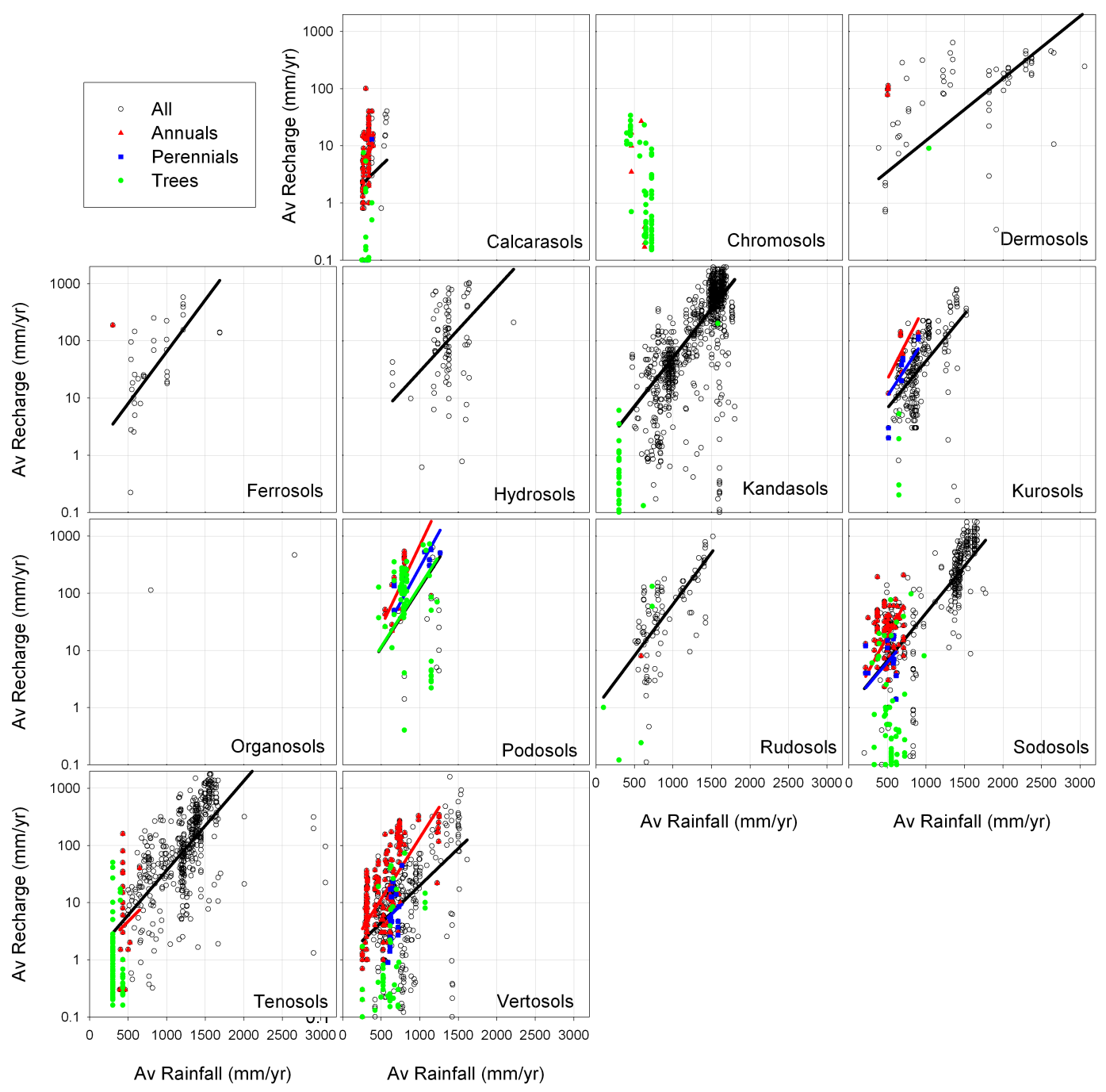

Fig. 10. The relationship between rainfall and recharge when categorised by soil order. The class "all" is all the recharge estimates irrespective of vegetation type.

sands and are found in high recharge areas such as Gnangara (WA) and Tomago (NSW). The Sodosols (SO) and Kurosols (KU) were not significantly different from each other for the annual and perennial vegetation types; this could be attributed to both soils being duplex. The Vertosols (VE) had less recharge for a given rainfall than the duplex soils for annual and perennial vegetation but not statistically significantly lower. Overall, the results suggest that soils are a key determinant in recharge prediction, as has been previously shown by studies such as Kennett-Smith et al. (1994).

\subsection{A simple empirical method for estimating recharge in data-poor areas}

To develop a simple empirical method for estimating recharge in data-poor areas we used the information gained from investigating the different factors affecting recharge.
The method used to estimate recharge had an influence over the magnitude of the recharge estimate but the different methods are not necessarily incompatible. The only inappropriate estimates of recharge for this purpose are those where the author noted that the estimate of recharge was of net recharge. These estimates will produce a low bias because they have evapotranspiration from the saturated zone included in the net recharge estimate; therefore they have been excluded from further analysis.

Vegetation was shown to have a very strong control over recharge so the three vegetation classes were used in further analysis.

The Köppen-Geiger classification of climate zones did not produce enough information to say definitively that recharge from summer dominated rainfall was different from recharge from winter dominated rainfall; therefore it has not been used in further analysis. The aridity index did not show that the 


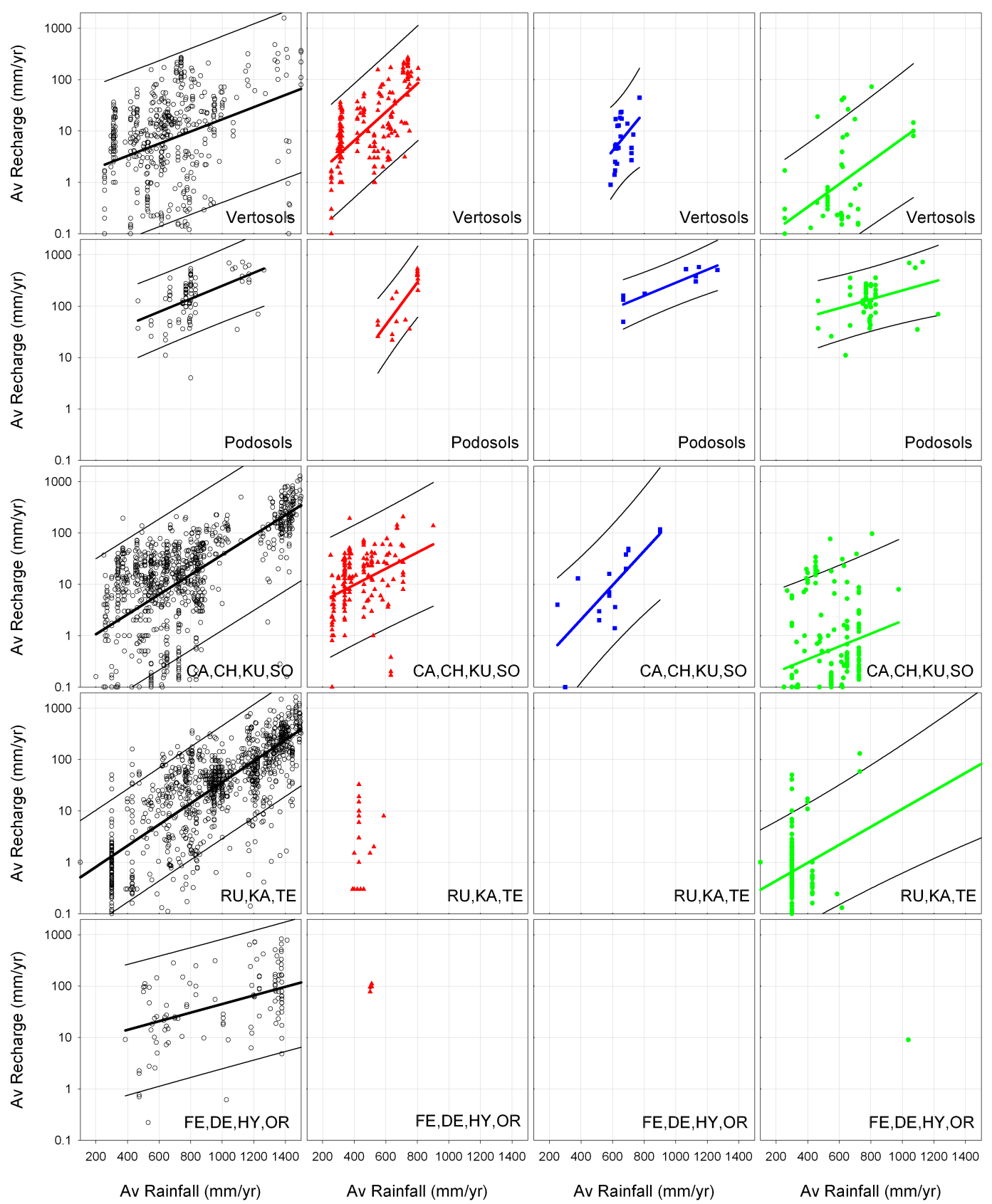

Fig. 11. Relationships between average annual rainfall and average annual recharge for the combination of soil and vegetation groups. The line of best fit is the bold colour line while the thin black line is the $95 \%$ prediction interval about the line of best fit. The annual vegetation class is displayed in red, the annuals in blue and the trees in green. In black is all the recharge estimates irrespective of vegetation type.

different classes were relevant to recharge except for where PET/P was greater than 0.75 . Recharge estimates from these areas were excluded from further analysis because there was no relationship between recharge and rainfall for the data that we had available.

The classes of surface geology examined here did not prove to be useful for estimating recharge and were not used for further analysis. The classes of soil order were useful for estimating recharge although there was insufficient data available to produce rainfall - recharge relationships for all 13 soil orders. The 13 soil orders were aggregated into 5 groups:

1. the Vertosols (VE) were different from the other soils due to being cracking clays with a high clay content and therefore formed their own group 
Table 1. Regression equations for lines in Fig. 11.

\begin{tabular}{lrrrrrrrrrrrr}
\hline & \multicolumn{3}{c}{ All } & \multicolumn{4}{c}{ Annuals } & \multicolumn{3}{c}{ Perennials } & \multicolumn{3}{c}{ Trees } \\
Soil Group & $a$ & $b$ & $r^{2}$ & $a$ & $b$ & $r^{2}$ & $a$ & $b$ & $r^{2}$ & $a$ & $b$ & $r^{2}$ \\
\hline VE & $1.18 \mathrm{E}-03$ & 0.04 & 0.20 & $2.78 \mathrm{E}-03$ & -0.30 & 0.42 & $3.77 \mathrm{E}-03$ & -1.65 & 0.16 & $2.22 \mathrm{E}-03$ & -1.37 & 0.37 \\
PO & $1.27 \mathrm{E}-03$ & 1.13 & 0.29 & $4.16 \mathrm{E}-03$ & -0.86 & 0.64 & $1.27 \mathrm{E}-03$ & 1.19 & 0.77 & $8.63 \mathrm{E}-04$ & 1.44 & 0.17 \\
CA, CH, KU, SO & $1.93 \mathrm{E}-03$ & -0.36 & 0.54 & $1.58 \mathrm{E}-03$ & 0.36 & 0.11 & $3.34 \mathrm{E}-03$ & -1.02 & 0.58 & $1.24 \mathrm{E}-03$ & -0.96 & 0.05 \\
RU, KA, TE & $2.06 \mathrm{E}-03$ & -0.50 & 0.69 & & & & & & & $1.75 \mathrm{E}-03$ & -0.71 & 0.14 \\
FE, DE, HY, OR & $8.39 \mathrm{E}-04$ & 0.81 & 0.26 & & & & & & & & \\
\hline
\end{tabular}

Note: $\mathrm{VE}=$ Vertosols, $\mathrm{PO}=$ Podosols, $\mathrm{CA}=$ Calcarosols, $\mathrm{CH}=$ Chromosols, $\mathrm{KU}=$ Kurosols, $\mathrm{SO}=$ Sodosols, $\mathrm{RU}=\mathrm{Rudosols}$, $\mathrm{KA}=$ Kandosols, $\mathrm{TE}=$ Tenosols, $\mathrm{FE}=$ Ferrosols, $\mathrm{DE}=$ Dermosols, $\mathrm{HY}=$ Hydrosols, $\mathrm{OR}=$ Organosols

2. the Podosols (PO) had the highest recharge of any soil order and therefore formed their own group

3. the Sodosols (SO) and Kurosols (KU) were not significantly different from each other and therefore combined into a group. Chromosols $(\mathrm{CH})$ are also duplex soils so were added into this group. The Calcarasols (CA) were not significantly different from the other soils in this group so were added to it.

4. the Kandasols (KA) and Rudosols (RU) were not significantly different from each other and were therefore combined into a group. The Tenosols (TE) were added into this group due to being similar soils.

5. the last group of soils posed a problem due to lack of data. The Dermosols (DE), Ferrosols (FE), Organosols (OR) and Hydrosols (HY) were combined together due to being similar soils and not having enough information to split them apart.

The one parameter model that was used had some difficulty in fitting some of the data, particularly under the tree vegetation type where recharge was very low. To overcome this, a two parameter model was used here:

$R=10^{a P+b}$

where $a$ and $b$ are the fitting parameters from a least squares regression between annual average rainfall and the logarithm of annual average recharge.

The relationships developed between average annual rainfall and average annual recharge for the soil and vegetation groupings are shown in Fig. 11 and the parameters used in the regression equations are shown in Table 1 . No line was plotted on Fig. 11 or parameters listed in Table 1 where the relationship was not statistically significant $(P<0.05)$. The relationships developed are mixed in the strength of their correlation. When ranked on the strength of their correlations, the top third of relationships developed have an $r^{2}$ of above 0.5 while the bottom third have an $r^{2}$ of below 0.2. This means that the relationships developed using average annual rainfall, vegetation type and soil group cannot explain all the variation in the recharge estimates, not that we would expect them to considering the heterogeneity within the soils and vegetation groupings. The prediction intervals around the line of best fit were very wide; only the relationships developed for the Podosol soils had prediction intervals less than an order of magnitude either side of the line of best fit. Overall, the regression equations developed here are able to explain $60 \%$ of the variation in the field estimates of recharge (Fig. 12).

The form of the relationships developed between annual average rainfall and annual average recharge for combinations of soil and vegetation types is very similar to the relationships used in a recent modelling paper over a substantial part of Australia (Crosbie et al., 2010b).

\subsection{Limitations}

The intention of this work was to provide a simple means of estimating recharge in data-poor areas where detailed work was not warranted. The relationships developed here only rely upon the average annual rainfall, the soil type and the vegetation type; all of these can be determined from national scale mapping.

There were very few recharge estimates where the original author had assigned a soil type to the recharge estimates; this necessitated assigning a soil type to each recharge estimate based upon the co-ordinates of the point at which the recharge estimate was made. The soil mapping used here is national scale with soils mapped as the dominant soil within the polygon. Soils exhibit metre scale heterogeneity and the soil type will vary down a hillslope, all within the same polygon on a map. There will be inaccuracies in the soil that was assigned to each field estimate of recharge but these inaccuracies are consistent with the intended use of the relationships developed.

A vegetation type was not assigned to each recharge estimate in the same way as soil types were assigned. This was due to the temporal nature of vegetation and that many of the recharge studies were conducted to investigate the impacts of land use change upon recharge. Vegetation type was only 


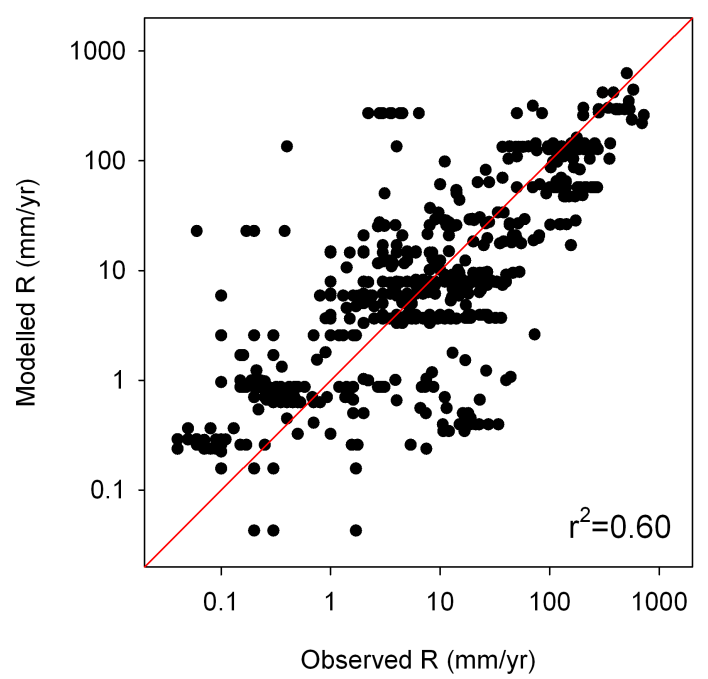

Fig. 12. Relationship between the field estimates of recharge and the estimates of recharge from the regression equations in Fig. 11.

used to build the relationships between rainfall and recharge where the author of the study that provided the recharge estimate also provided a vegetation type to associate with it. About a quarter of all recharge estimates used here had a vegetation type associated with it (Fig. 1). The recharge estimates that did not have a vegetation type associated with it were used in the "all" category, this category consists of all of the data (irrespective of whether vegetation type has been specified or not) and has limited value due to the dominance of vegetation type over recharge.

The relationships developed here had a lot of scatter about the line of best fit. The $95 \%$ prediction interval was greater than an order of magnitude either side of the line of best fit in most cases. This demonstrates the uncertainty in the relationships developed. If these relationships were to be used on a regional basis then the uncertainty would be overstated as very few $(<1 \%)$ of the recharge estimates are at a scale larger than a paddock.

If these relationships were to be used to estimate recharge for the purpose of water allocations, then the prediction limits must be taken into account. The precautionary principle would restrict water allocations to be less than about $5 \%$ of the recharge estimated using the line of best fit because the uncertainty in these relationships is generally greater than an order of magnitude. If water was to be allocated to a level greater than the lower prediction interval then a more detailed site specific study is warranted.

\section{Conclusions}

Using a database of 4386 field based recharge estimates from 172 studies throughout Australia key factors controlling recharge were investigated. The key factors investigated in this study were: vegetation type; climate; and, surface material along with the method used to estimate the recharge.

The method used to estimate recharge can have an influence over the magnitude of recharge because the quantity measured by different methods is not the same. Methods that estimate potential recharge (e.g. Cl Transient Soil) gave a different recharge estimate than those methods that estimate actual recharge (e.g. Cl SS GW) if the system was not in equilibrium, such as after a land use change. Methods that estimate gross recharge (e.g. WTF) gave different estimates of recharge to those that estimate net recharge (e.g. Cl SS GW) in areas with shallow water tables and phreatophytic vegetation. Where the different methods used were estimating the same quantity the magnitude of the recharge estimates was found to be more consistent (e.g. WTF and CFC).

The vegetation type was found to be a critical determinant in estimating recharge. Recharge under annual vegetation was found to be greater than recharge under perennial vegetation which in turn was greater than recharge under the tree type vegetation. At the extreme, annual vegetation had recharge that was two orders of magnitude greater than the native vegetation that it replaced.

Using Köppen-Geiger climate classes as a basis for investigating whether winter dominated rainfall produced more recharge than summer dominated rainfall for a given annual average rainfall proved to be inconclusive. Although the winter dominated rainfall areas had greater recharge for a given annual average rainfall this could also be explained on the basis of soil type. The climate zones examined here did not appear to be a key factor controlling recharge.

The surface geology did not prove to be useful in predicting recharge but soil type was a strong determinant in the rainfall - recharge relationship. Podosols had the most recharge for a given rainfall and the Vertosols and duplex soils had the least.

The results of the investigation into the factors that control recharge led to the creation of a series of empirical relationships between average annual rainfall and average annual recharge for combinations of vegetation and soils groupings. These relationships can be used to estimate recharge in data-poor areas where a detailed field study is not warranted. The limitation on these empirical relationships is the uncertainty surrounding the prediction. The $95 \%$ prediction interval around the line of best fit is generally greater than an order of magnitude in each direction. This would suggest that if these relationships are used to help determine water allocations then the precautionary principle should limit allocations to less than about $5 \%$ of the estimated recharge, if allocations are greater than this a more detailed site specific study is warranted. 
A comparison of the rainfall-recharge relationship developed by Scanlon et al. (2006) for recharge under native vegetation to that developed here suggests that recharge for a given annual average rainfall is less in Australia compared to that from the rest of the world. This could be a result of the highly efficient vegetation that has evolved in Australia.

\section{Supplementary material related to this article is available online at: http://www.hydrol-earth-syst-sci.net/14/2023/2010/ hess-14-2023-2010-supplement.zip.}

Acknowledgements. This paper is a product of the "A Consistent Approach to Groundwater Recharge Determination in Data-Poor Areas" project which is funded by the National Water Commission.

Edited by: Y. Fan

\section{References}

Allison, G. B. and Hughes, M. W.: The use of Environmental Chloride and Tritium to Estimate Total Recharge to an Unconfined Aquifer, Aust. J. Soil Res., 16, 181-195, 1978.

Allison, G. B., Stone, W. J., and Hughes, M. W.: Recharge in Karst and Dune Elements of a Semi-Arid Landscape as Indicated by Natural Isotopes and Chloride, J. Hydrol., 76, 1-25, 1985.

Anderson, V. G.: Some effects of atmospheric evaporation and transpiration on the composition of natural water in Australia (continued). 4. Underground waters in riverless areas, J. Aust. Chem. Inst., 12, 83-98, 1945.

Bosch, J. M. and Hewlet, J. D.: A review of catchment experiments to determine the effect of vegetation changes on water yield and evapotranspiration, J. Hydrol., 55, 3-23, 1982.

Bowman, D. and Prior, L.: Turner Review No. 10 - Why do evergreen trees dominate the Australian seasonal tropics?, Aust. J. Bot., 53, 379-399, 2005.

BRS: Integrated Vegetation Cover 2008, Bureau of Rural Sciences, Canberra, 2008.

Canadell, J., Jackson, R. B., Ehleringer, J. R., Mooney, H. A., Sala, O. E., and Schulze, E. D.: Maximum rooting depth of vegetation types at the global scale, Oecologia, 108, 583-595, 1996.

Cartwright, I., Weaver, T. R., Stone, D., and Reid, M.: Constraining modern and historical recharge from bore hydrographs, H-3, C-14 and chloride concentrations: Applications to dual-porosity aquifers in dryland salinity areas, Murray Basin, Australia, J. Hydrol., 332, 69-92, 2007.

Cartwright, I. and Simmonds, I.: Impact of changing climate and land use on the hydrogeology of southeast Australia, Aust. J. Earth Sci., 55, 1009-1021, 2008.

Cook, P. G., Leaney, F. W., and Jolly, I. D.: Groundwater Recharge In The Mallee Region, And Salinity Implications For The Murray River - A Review, CSIRO Land and Water Technical Report 45/01, Adelaide, 2001.

Crosbie, R. S., Binning, P., and Kalma, J. D.: The Spatial and Temporal Variability of Groundwater Recharge Estimates From Time Series Analysis, Third International Conference on Water Resources and Environment Research, Dresden, Germany, 2002.
Crosbie, R. S., Jolly, I. D., Leaney, F. W., Petheram, C., and Wohling, D.: Review of Australian groundwater recharge studies, CSIRO Water for a Healthy Country National Research Flagship, Canberra, 79 pp., 2010a.

Crosbie, R. S., McCallum, J. L., Walker, G. R., and Chiew, F. H. S.: Modelling climate change impacts on groundwater recharge in the Murray-Darling Basin, Australia, Hydrogeol. J., 18, 16391656, 2010b.

de Vries, J. J. and Simmers, I.: Groundwater Recharge: An Overview of Processes and Challenges, Hydrogeol. J., 10, 5-17, 2002.

Donohue, R. J., McVicar, T. R., and Roderick, M. L.: Assessing the ability of potential evaporation formulations to capture the dynamics in evaporative demand within a changing climate, J. Hydrol., 386, 186-197, 2010.

Eagleson, P. S.: Ecological optimality in water-limited natural soilvegetation systems. 1 . Theory and hypothesis, Water Resour. Res., 18, 325-340, 1982.

Herczeg, A. L., Dogramaci, S. S., and Leaney, F. W. J.: Origin of dissolved salts in a large, semi-arid groundwater system: Murray Basin, Australia, Mar. Freshwater Res., 52, 41-52, 2001.

Isbell, R. F.: Australian Soils Classification, CSIRO, Collingwood, Victoria, 144 pp., 2002.

Jeffrey, S. J., Carter, J. O., Moodie, K. B., and Beswick, A. R.: Using spatial interpolation to construct a comprehensive archive of Australian climate data, Environ. Modell. Softw., 16, 309330, 2001.

Johnston, R. M., Barry, S. J., Bleys, E., Bui, E. N., Moran, C. J., Simon, D. A. P., Carlile, P., McKenzie, N. J., Henderson, B. L., Chapman, G., Imhoff, M., Maschmedt, D., Howe, D., Grose, C., Schoknecht, N., Powell, B., and Grundy, M.: ASRIS: the database, Aust. J. Soil Res., 41, 1021-1036, 2003.

Jolly, I. D., Cook, P. G., Allison, G. B., and Hughes, M. W.: Simultaneous water and solute movement through an unsaturated soil following an increase in recharge, J. Hydrol., 111, 391-396, 1989.

Kennett-Smith, A., Cook, P. G., and Walker, G. R.: Factors affecting groundwater recharge following clearing in the south western Murray Basin, J. Hydrol., 154, 85-105, 1994.

Leaney, F. W., Herczeg, A. L., and Walker, G. R.: Salinization of a Fresh Palaeo-Ground Water Resource by Enhanced Recharge, Ground Water, 41, 84-92, 2003.

Lerner, D. N., Issar, A. S., and Simmers, I.: Groundwater Recharge - A Guide to Understanding and Estimating Natural Recharge, IAH, Hanover, 1990.

Liu, S. F., Raymond, O. L., Stewart, A. J., Sweet, I. P., Duggan, M. B., Charlick, C., Phillips, D., and Retter, A. J.: Surface geology of Australia 1:1,000,000 scale, Northern Territory [Digital Dataset], The Commonwealth of Australia, Geoscience Australia, http://www.ga.gov.au, Canberra, 2006.

Meinzer, O. E. and Stearns, N. D.: A Study of Groundwater in the Pomperaug Basin, Conn. with Special Reference to Intake and Discharge, US Geol. Surv. Water Supply Paper, Pap 597B, 1929.

O'Grady, A. P., Cook, P. G., Eamus, D., Duguid, A., Wischusen, J. D. H., Fass, T., and Worldege, D.: Convergence of tree water use within an arid-zone woodland, Oecologia, 160, 643-655, 2008.

Peel, M. C., McMahon, T. A., Finlayson, B. L., and Watson, F. G. R.: Identification and explanation of continental differences in the variability of annual runoff, J. Hydrol., 250, 224-240, 2001. 
Peel, M. C., Finlayson, B. L., and McMahon, T. A.: Updated world map of the Koppen-Geiger climate classification, Hydrology and Earth System Sciences, 11, 1633-1644, 2007.

Penman, H. L.: Evaporation from forests: a comparison of theory and observation, International symposium on forest hydrology, Permagon Press, Oxford, England, 373-380, 1967.

Petheram, C., Walker, G., Grayson, R., Thierfelder, T., and Zhang, L.: Towards a framework for predicting impacts of land-use on recharge: 1. A review of recharge studies in Australia, Aust. J. Soil Res., 40, 397-417, 2002.

Radford, B. J., Silburn, D. M., and Forster, B. A.: Soil chloride and deep drainage responses to land clearing for cropping at seven sites in central Queensland, northern Australia, J. Hydrol., 379, 20-29, 2009.

Raymond, O. L., Liu, S. F., and Kilgour, P.: Surface geology of Australia 1:1,000,000 scale, Tasmania - 3rd edition [Digital Dataset], Geoscience Australia, http://www.ga.gov.au, Canberra, 2007a.

Raymond, O. L., Liu, S. F., Kilgour, P., Retter, A. J., and Connolly, D. P.: Surface geology of Australia 1:1,000,000 scale, Victoria 3rd edition [Digital Dataset], Geoscience Australia, http://www. ga.gov.au, Canberra, 2007b.

Raymond, O. L., Liu, S. F., Kilgour, P., Retter, A. J., Stewart, A. J., and Stewart, G.: Surface geology of Australia 1:1,000,000 scale, New South Wales - 2nd edition [Digital Dataset], Geoscience Australia, http://www.ga.gov.au, Canberra, 2007c.

Scanlon, B. R., Healy, R. W., and Cook, P. G.: Choosing Appropriate Techniques for Quantifying Groundwater Recharge, Hydrogeol. J., 10, 18-39, 2002.

Scanlon, B. R., Keese, K. E., Flint, A. L., Flint, L. E., Gaye, C. B., Edmunds, W. M., and Simmers, I.: Global synthesis of groundwater recharge in semiarid and arid regions, Hydrol. Process., 20, 3335-3370, 2006.

Silberstein, R. P.: Review of Recharge and Water Use Studies of Vegetation on Gnangara Groundwater Mound, CSIRO Land and Water Science Report, Perth, 2010.
Stewart, A. J., Sweet, I. P., Needham, R. S., Raymond, O. L., Whitaker, A. J., Liu, S. F., Phillips, D., Retter, A. J., Connolly, D. P., and Stewart, G.: Surface geology of Australia 1:1,000,000 scale, Western Australia [Digital Dataset], Geoscience Australia, http://www.ga.gov.au, Canberra, 2008.

Thorburn, P. J., Rose, C. W., Shaw, R. J., and Yule, D. F.: SODICS: A program to calculate solute dynamics in irrigated clay soils, in: Proceedings of Bundaberg Regional Salinity workshop, Conference and Workshop Series QC87001 Department of Primary Industries, Brisbane, 1987.

Tolmie, P. E., and Silburn, D. M.: Estimating Deep Drainage In The Queensland Murray-Darling Basin: Review of Past Research, Queensland Department of Natural Resources and Mines Report QNRM04100, Toowoomba, 2003.

UNEP: World atlas of desertification, United Nations Environment Program, 182 pp., 1992.

Walker, G. R., Jolly, I. D., and Cook, P. G.: A new chloride leaching approach to the estimation of diffuse recharge following a change in land use, J. Hydrol., 128, 49-67, 1991.

Whitaker, A. J., Champion, D. C., Sweet, I. P., Kilgour, P., and Connolly, D. P.: Surface geology of Australia 1:1,000,000 scale, Queensland - 2nd edition [Digital Dataset] Geoscience Australia, http://www.ga.gov.au, Canberra, 2007.

Whitaker, A. J., Glanville, H. D., English, P. M., Stewart, A. J., Retter, A. J., Connolly, D. P., Stewart, G. A., and Fisher, C. L.: Surface geology of Australia 1:1,000,000 scale, South Australia - 1st edition [Digital Dataset] Geoscience Australia, http://www. ga.gov.au, Canberra, 2008.

Wohling, D.: Deep drainage versus percentage clay content relationship explored based on rainfall, in preparation, 2010.

Wood, W. E.: Increase in salt in soil and streams following the destruction of the native vegetation, J. R. Soc. W. A., 10, 35-47, 1924. 